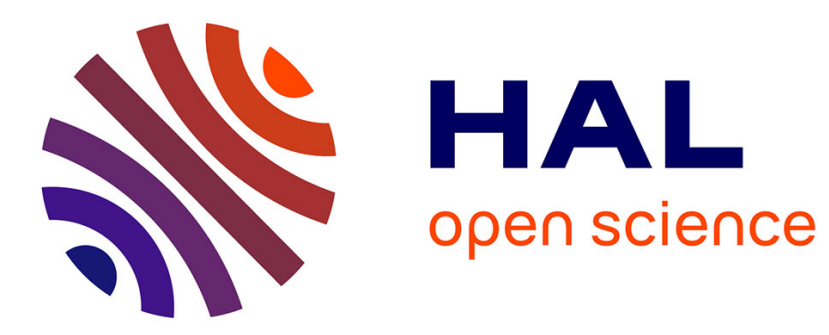

\title{
Actuation means for the mechanical stimulation of living cells via microelectromechanical systems: A critical review
}

\author{
Denis Desmaële, Mehdi Boukallel, Stéphane Régnier
}

\section{- To cite this version:}

Denis Desmaële, Mehdi Boukallel, Stéphane Régnier. Actuation means for the mechanical stimulation of living cells via microelectromechanical systems: A critical review. Journal of Biomechanics, 2011, 44, pp.1433-1446. 10.1016/j.jbiomech.2011.02.085 . hal-01159531

\section{HAL Id: hal-01159531 \\ https://hal.science/hal-01159531}

Submitted on 3 Jun 2015

HAL is a multi-disciplinary open access archive for the deposit and dissemination of scientific research documents, whether they are published or not. The documents may come from teaching and research institutions in France or abroad, or from public or private research centers.
L'archive ouverte pluridisciplinaire HAL, est destinée au dépôt et à la diffusion de documents scientifiques de niveau recherche, publiés ou non, émanant des établissements d'enseignement et de recherche français ou étrangers, des laboratoires publics ou privés. 


\title{
Actuation means for the mechanical stimulation of living cells via microelectromechanical systems: a critical review
}

\author{
Denis Desmaële $\mathrm{a}^{\mathrm{a}, \mathrm{b}, *}$, Mehdi Boukallel $^{\mathrm{a}}$, Stéphane Régnier ${ }^{\mathrm{b}}$ \\ ${ }^{a}$ CEA, LIST, Sensory Ambient Interface Laboratory, 18 Route du Panorama, BP6, \\ Fontenay-aux-Roses, F-92265, France; \\ ${ }^{b}$ Institute of Intelligent System and Robotics, University of Pierre et Marie Curie, CNRS UMR \\ 7222, 4 Place Jussieu, Paris, 75005, France;
}

\begin{abstract}
Within a living body, cells are constantly exposed to various mechanical constraints. As a matter of fact, these mechanical factors play a vital role in the regulation of the cell state. It is widely recognized that cells can sense, react and adapt themselves to mechanical stimulation. However, investigations aimed at studying cell mechanics directly in vivo remain elusive. An alternative solution is to study cell mechanics via in vitro experiments. Nevertheless, this requires implementing means to mimic the stresses that cells naturally undergo in their physiological environment. In this paper, we survey various microelectromechanical systems (MEMS) dedicated to the mechanical stimulation of living cells. In particular, we focus on their actuation means as well as their inherent capabilities to stimulate a given amount of cells. Thereby, we report actuation means dependent upon the fact they can provide stimulation to a single cell, target a maximum of a hundred cells, or deal with thousands of cells. Intrinsic performances, strengths and limitations are summarized for each type of actuator. We also discuss recent achievements as well as future challenges of cell mechanostimulation.
\end{abstract}

Keywords: Cell mechanostimulation, cell stretching, cell loading, cell 
indentation, microelectromechanical systems (MEMS).

\section{Introduction}

2

It is widely recognized that mechanical and biochemical cues occurring at the

3 cellular level prove to be intimately correlated through reciprocal mechanochem-

4 ical conversion pathways. Indeed, numerous studies have highlighted the fact

5 that surrounding mechanical stresses sensed by a cell may elicit cellular bio-

6 chemical signals, which in turn may direct and mediate intricate cellular pro-

cesses. Thereby, externally applied forces may induce profound effects on cel-

8 lular functions as essential as apoptosis (programmed cell death), growth, pro-

9 liferation, contractility, migration or differentiation (see Bao and Suresh, 2003;

1 Wang and Thampatty, 2006; Janmey and McCulloch, 2007; Lele et al., 2007;

11 Hoffman and Crocker, 2009 and references therein). This aptitude to modulate

12 cell biochemical reactions constitutes the essence of a very active field of re-

search which might lead to promising applications in biotechnology as well as in

medicine. Dysfunctions in mechanotransduction processes contribute to the un-

derlying causes of major diseases including osteoporosis, hypertension, asthma,

malaria or cancer (Lee and Lim, 2007). By regulating cellular biochemical re-

7 actions via proper mechanical signals, development of pathological conditions might be ideally limited. For instance, one might ultimately envision cell-based

therapies wherein mechanical effects on cell fate and growth could affect tissue

20 remodeling and regeneration (Kim et al., 2009a)

\footnotetext{
*Corresponding author. Tel.:+331 465488 25; fax: +331 46548980 .

Email addresses: denis.desmaele@cea.fr(Denis Desmaële), mehdi.boukallel@cea.fr (Mehdi Boukallel), stephane.regnier@upmc.fr (Stéphane Régnier) 
Several articles have already reviewed the large panel of experimental techniques and microelectromechanical systems (MEMS) reported for conducting mechanobiology studies at the cell level (Van Vliet et al., 2003; Huang et al., 2004; Geitmann, 2006; Addae-Mensah and Wikswo, 2008; Norman et al., 2008; Loh et al., 2009; Sen and Kumar, 2010). These references have usually discussed tools for cell mechanics at a systemic level, whereas very few reports have independently analyzed the actuation or measurement principles involved in these systems. To the best of our knowledge, only Brown proposed a review focused on actuation techniques intending to replicate the different types of mechanical stresses that cells face in vivo (Brown, 2000). Brown discussed systems able to mimic compressive strains (cartilage and bone cells experience compressive loads), elongations (lung and heart cells endure stretching cycles during breathing and beating), as well as shear stresses (in blood vessels, cells are continuously subjected to fluid shear stress from blood flow). However, Brown's review focused mainly on early laboratory apparatus which were only able to address large cell cultures or tissues. Meanwhile, recent advances in microfabrication techniques have facilitated interactions with isolated cells and more realistic complex cellular environment. Thereby, MEMS appear today as ideal interfaces to integrate more in vivo-like stimuli in in vitro settings.

The aim of this paper is to provide an updated overview of actuation techniques dedicated to the mechanical stimulation of living cells via MEMS. In particular, we report initial characterization of principles as a function of their inherent capabilities to target a given amount of cells. Hereafter, sections present various MEMS intended for the stimulation of a single cell, tens of cells (e.g., maximum 200 cells), and large populations of cells (e.g., minimum $10^{4}$ cells). Finally, discussion of the strengths and limitations for each methodology and a 
comparative analysis are also included.

\section{MEMS for the mechanical stimulation of one cell}

This section introduces several MEMS that have been reported in the literature for the mechanical stimulation of a single isolated cell. By definition, the terminology MEMS employed throughout the paper will refer to systems encompassing electrical, optical, or mechanical parts manufactured via microfabrication processes. It is however worth noticing that the presence of microscopic components is not always a sufficient condition to consider a system as a MEMS. For instance, micropipettes (e.g., Evans and Yeung, 1989; Sato et al., 1990; Miyazaki et al., 2000) or microcantilevers used in atomic force microscopes (e.g., Lekka et al., 1999; van der Rijt et al., 2006; Li et al., 2008; Cross et al., 2008; Pillarisetti et al., 2008; Boukallel et al., 2009) are usually considered as experimental tools by the research community (see for instance the classification adopted in the reviews of Kim et al., 2009a or Loh et al., 2009). Accordingly, and even though they are implicitly considered later in our analysis, they will not be described in details in this paper.

In order to avoid too many subcategories in our classification, we also state the following assumptions. Although mechanical stimuli can be applied upon cells either by a controlled force or a controlled displacement, actuation means are reported hereafter independent of the type of physical input. Similarly, no particular distinction is made between systems providing stimulation globally (i.e., stimulation is provided to the entire cell structure) or locally (i.e., only a given cellular region is excited). In addition, we do not differentiate actuation means as a function of the type of cells they can target (i.e., adherent or suspended cells). Finally, the consideration of auxiliary equipments (e.g., laser 
72 sources, peristaltic pumps, electric power supplies) is out of the scope of this 73 paper.

\subsection{Electromagnetic fields}

Magnetic fields have been used for studying the physical properties of cell cultures for decades (e.g., Crick and Hughes, 1950). However, technological evolutions have been recently reported with the manufacturing of microscopic magnetic manipulators able to locally stress an isolated cell (e.g., Chiou et al., 2006; Kanger et al., 2008; Yapici et al., 2008). For instance, in (de Vries et al., 2004, 2005), the authors implemented three magnetic micropoles on a glass substrate (see Fig. 1) in order to enable the stimulation of one cell in two dimensions. Each pole tip was $4 \mu \mathrm{m}$ wide, $6 \mu \mathrm{m}$ thick and had a surface roughness of $0.5 \mu \mathrm{m}$. Poles spacing was about $20 \mu \mathrm{m}$ to ensure the placement of a single cell between them. To transfer mechanical stimuli, magnetic microspheres were functionalized (i.e. coated with biochemicals) to allow their binding to specific cellular receptors. Once anchored, such microbeads could act as handles. Indeed, in the presence of a spatially varying magnetic field, the force $F_{m a g}$ experienced by such a magnetic particle is:

$$
F_{\text {mag }}=\nabla(m \cdot B)
$$

where $m$ is the magnetic moment of the microparticle and $B$ is the magnetic flux density. Assuming the induced moment is parallel to the magnetic field, and the field is large enough such that the magnetization of the particle saturates, the force acting on the magnetic particle can be approximated by the equation:

$$
F_{\text {mag }}=M V \frac{d B}{d x}
$$


where $M$ and $V$ are the magnetization and the volume of the particle, respectively. Thereby, by controlling the amplitude and the direction of the magnetic

77 flux gradient generated at the center of the three micropoles, de Vries et al. ex-

78 perimentally validated actuation forces up to $12 \mathrm{pN}$ on magnetic microbeads of $350 \mathrm{~nm}$ diameter.

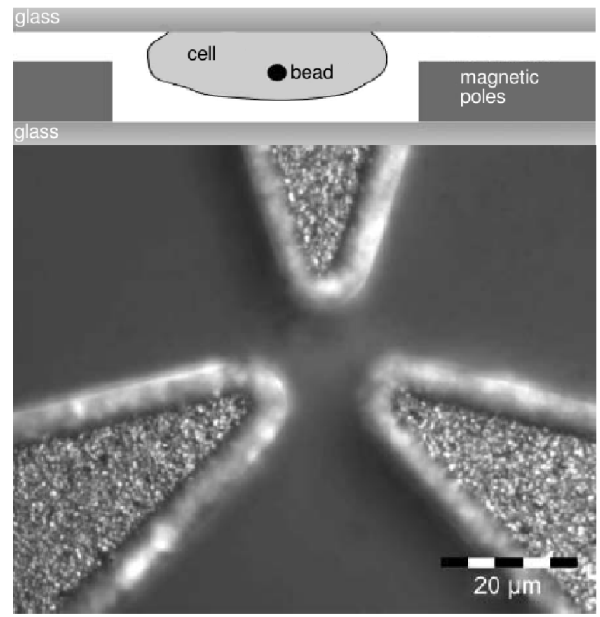

Figure 1: Top: sketch illustrating the setup designed by de Vries et al.: a cell anchored to a glass plate and embedding a magnetic microbead is placed between the tips of magnetic poles. Bottom: microscope image showing the extremities of three magnetic micropoles. Images adapted from (de Vries et al., 2005)

\subsection{Microactuators generating electric fields}

Non-uniform electric fields offer an alternative option to physically deform 82 an isolated cell (e.g., Engelhardt and Sackmann, 1988; Wong et al., 2005; Riske 83 and Dimova, 2006; Dimova et al., 2007; Guido et al., 2010; MacQueen et al., 84 2010). Indeed, when a cell is subjected to an electric field, a dipole can be in85 duced due to interfacial polarization on the cell membrane. Depending on the 86 electric field strength and the effective polarization of the cell, stress can then 
87 occur at the interfaces and result in a deforming force. During minor deforma88 tion, the elastic strain of the cell along the electric field direction is estimated as 89 (Sukhorukov et al., 1998):

$$
\frac{\Delta L_{C}}{L_{C 0}}=K_{S} E^{2} \operatorname{Re}[U(\omega)]
$$

90 where $\Delta L_{C}$ represents the deformation of the cell, $L_{0 C}$ is the original length of 91 the cell, $K_{S}$ is a constant representing the elastic properties of the cell, $\omega$ is the 92 angular frequency of the $\mathrm{AC}$ electric field applied, and $U(\omega)$ is the complex 93 Clausius-Mossotti factor that depends on the internal structures of the cell and is 94 cell-type specific.
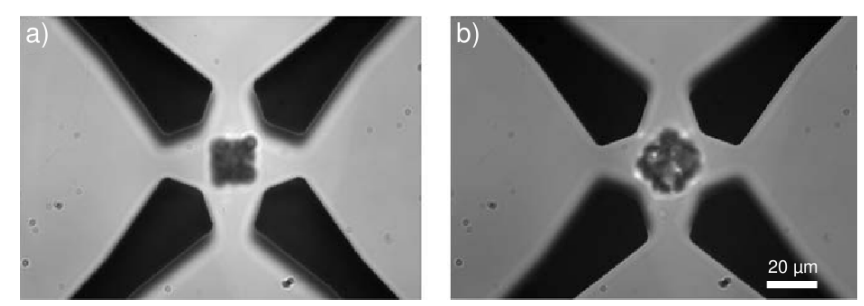

Figure 2: a) A GUV trapped between the electrodes of a microfield cage. b) The GUV is deformed by electric field. Images adapted from (Korlach et al., 2005)

Illustration of an octode microfield cage able to capture, hold, rotate and de-

form isolated giant unilamellar vesicles (GUVs) is given in Fig. 2 (Korlach et al., 2005). Modulation of the amplitude and frequency of the voltage applied to the electrode edges permitted the authors to conduct stretch and relax experiments on isolated GUVs, whose size ranged from 5 to $25 \mu \mathrm{m}$.

\subsection{Microactuators based on optical gradients}

Both refraction and reflection of light exert forces on all objects. If these forces are negligible in the macroworld, they become significant for microscopic 
objects weighing less than $1 \mu \mathrm{g}$. Thereby, light has been used to manipulate microparticles for four decades (e.g., Ashkin, 1970). Two optical fibers can be used to guide the light emanating from a laser source and create a dual beam laser trap system (e.g., Constable et al., 1993; Singer et al., 2003). In (Guck et al., 2001, 2002), the authors made use of optical fibers with a diameter of $125 \mu \mathrm{m}$ to trap and stretch biological entities. The divergent laser beams were directed at diametrically opposite portions of a suspended cell placed between them, as shown in Fig. 3. Often termed as optical stretcher (OS) in the literature, the net stretching force $F_{o s}$ exerted by such a configuration on a single cell can be expressed by the following equation (Van Vliet et al., 2003):

$$
\begin{aligned}
& F_{\text {os }}= \\
& \qquad \begin{array}{l}
\left(n_{m}-(1-R) n_{c}+R . n_{m}\right)\left(\frac{P}{c}\right)+ \\
\quad\left(n_{c}-(1-R) n_{m}+R . n_{c}\right)\left((1-R) \frac{P}{c}\right)
\end{array}
\end{aligned}
$$

\footnotetext{
where $n_{m}$ and $n_{c}$ are the refractive indices of the surrounding media and cell, respectively, $R$ is the fraction of reflected light, $c$ is the speed of light in vacuum, and $P$ is the total light power. With a $500 \mathrm{~mW}$ power laser source, this approach allowed Guck and co-workers to generate uniaxial stretching forces up to 400 $\mathrm{pN}$ in aqueous media. This facilitated cell elongations between 7-30 $\mu \mathrm{m}$. Guck et al. even predicted that given a higher power laser, the maximum stretching force could achieve or exceed $1 \mathrm{nN}$.
}

\subsection{Electrothermal microactuators}

Thermal expansion caused by electric currents heating up the material of a microstructure constitutes another well known actuation principle used in MEMS 

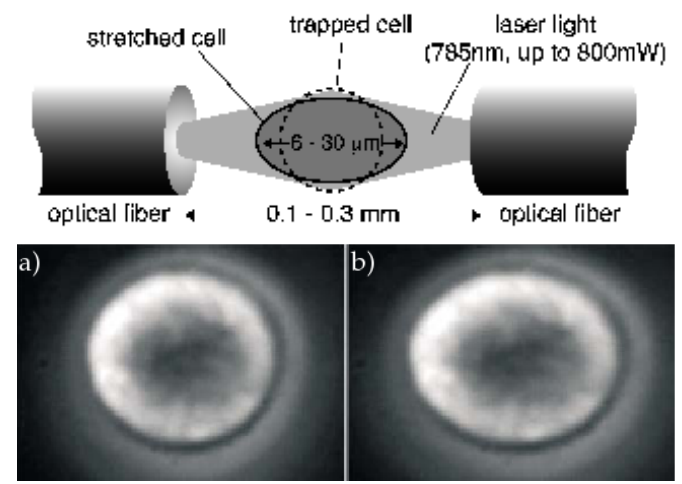

Figure 3: Top: representation of the all-fiber OS put forward by Guck et al. Bottom: a red blood cell, approximately $10 \mu \mathrm{m}$ in diameter, trapped by OS: before (a) and during (b) stretching (Guck et al., 2001, 2002) compliant beam is depicted in Fig. 4.

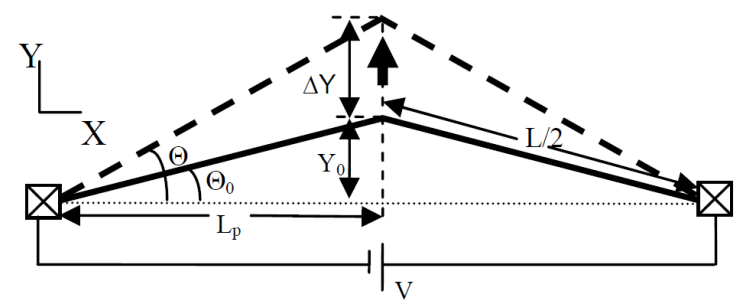

Figure 4: Main dimensions of a V-shaped beam (or chevron) anchored at its two ends: Joules heating causes thermal expansion and pushes the apex outward when an electric current passes through the structure (Kushkiev and Jupina, 2005)

126

Displacement of the beam apex $\Delta Y$ can be approximated via the formula (Girbau et al., 2003):

$$
\Delta Y=\left(\frac{L+\Delta_{L}}{2}\right) \sin \left[\arccos \left(\frac{2 L_{p}}{L+\Delta_{L}}\right)\right]-Y_{0}
$$


where $L$ is the total beam length, $L_{p}$ is the $X$ axis projection of $L / 2$, and $\Delta_{L}$ is the increment in length of the beam which can be expressed by:

$$
\Delta_{L}=\frac{\alpha q L^{3}}{12 k}
$$

In equation $6, \alpha$ is the thermal expansion coefficient, $k$ is the thermal conductivity, $q=V^{2} /(L w t R)$ is the heat generation per unit volume, $V$ is the voltage applied between anchors, whereas $w, t, R$ are the width, thickness and electrical resistance of the beam, respectively. Multiple pairs of such V-shaped beams can be serially combined in order to reach higher force displacement. Indeed, for small displacement, the total actuation force of several V-shaped beams can be approximated by:

$$
F_{\text {therm }}=N \frac{E w^{3} t}{4 L^{3}} \Delta Y
$$

\subsection{Electrostatic microactuators}

Many MEMS intended to the fatigue investigation of micro and nanomaterials have been actuated by interdigitated comb fingers exploiting electrostatic phenomena (e.g., Kahn et al., 1999; Kiuchi et al., 2007; Naraghi and Chasiotis, 2009; Takahashi et al., 2009). Biological applications have been reported by 


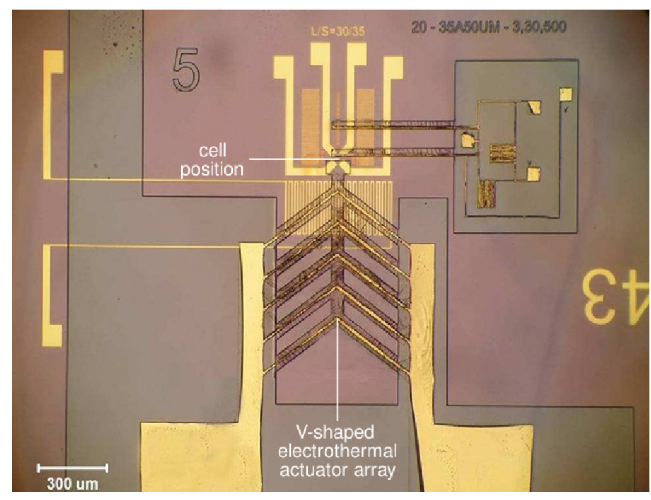

Figure 5: Electrothermal MEMS cell loader designed for measuring the compliance of cells. Image adapted from (Zhang et al., 2008)

Eppell et al. (2006) and Shen et al. (2008), who carried out stress-strain experiments on individual collagen fibrils. A multidimensional approach based on a single linear electrostatic structure was also reported by Scuor et al. (2006), who conceived a micro in-plane biaxial cell stretcher (see Fig. 6). The quadrants of a sliced circular plate were actuated in mutually-orthogonal directions, that is to say that the quadrants moved in horizontal and vertical directions simultaneously. The net force developed by such a comb drive actuator is given by:

$$
F_{\text {electro }}=N\left(\frac{\epsilon t}{g}\right) V^{2}
$$

where $\mathrm{N}$ is the number of comb electrodes, $\epsilon$ is the permittivity constant of the dielectric medium, $t$ is the comb thickness, $g$ is the comb electrode gap and $V$ is the driving voltage. Theoretically, Scuor et al. claimed that a nominal voltage of $100 \mathrm{~V}$ permitted such an electrostatic structure to generate actuation forces up to $60 \mu \mathrm{N}$. In practice, only translation amplitudes of the plate were reported. In ambient conditions, a power supply of $100 \mathrm{~V}$ led to a maximum space between the quadrants of $3.4 \mu \mathrm{m}$. 


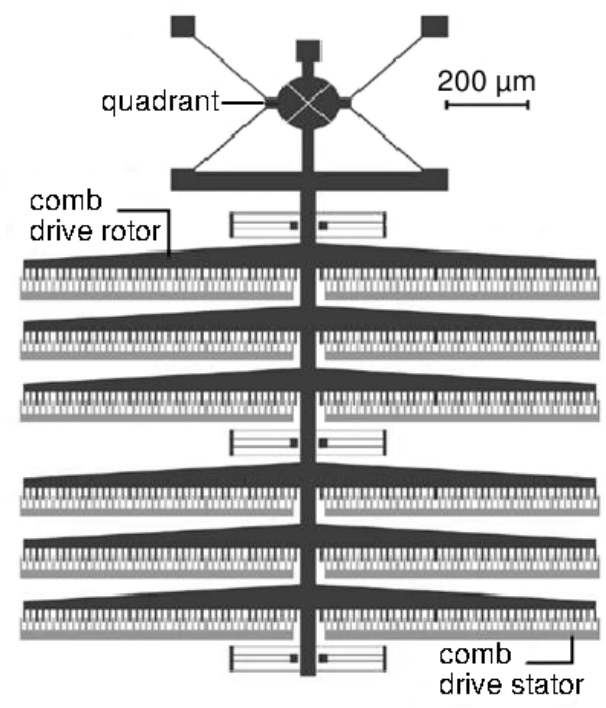

Figure 6: Illustration a comb drive system actuating a bi-axial cell stretcher. Drawing adapted from (Scuor et al., 2006)

\subsection{Micro-nanopositioning stages}

Commercial micro or nanopositioning stages (or micro-nanotranslators) may be classified as off-chip actuators. Unlike the actuation means presented so far, they are distantly linked to the microstructure they control (see Fig. 10 for an illustration). It is worth noticing that the prefix micro-nano often encountered in the literature is not related the size of these actuators, but to their displacement resolution. However, they are one of the most widespread option for ensuring the actuation of passive MEMS dedicated to the stimulation of cells. Thereby, positioning stages are conventionally used to actuate passive microstructures such as microplates (e.g., Thoumine et al., 1999; Desprat et al., 2006; Fernández et al., 2006; Gladilin et al., 2007; Chan et al., 2008) or microindenters (e.g., Koay et al., 2003; Peeters et al., 2005; Sato et al., 2007).

Similarly, positioning stages were used by Yang and Saif $(2005,2006,2009)$ 


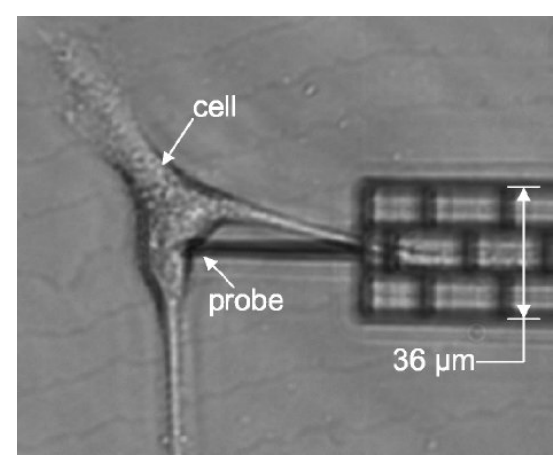

Figure 7: Microscope image of an adherent MKF indented in three dimensions by a force sensor (Yang and Saif, 2005)

to translate compliant microstructures. The extremity of such MEMS is shown in Fig.7. Piezoelectric stages offering an intrinsic resolution of $1 \mathrm{~nm}$ were selected in order to apply large strains to adherent fibroblasts in three dimensions. However, these stages were subsequently mounted on a $x-y-z$ mechanical station which lowered the resolution to $1 \mu \mathrm{m}$. During experiments, monkey kidney fibroblasts (MKFs) could be indifferently subjected to indentation or stretching with amplitude as large as $50 \mu \mathrm{m}$, which was about twice the initial size of the cells.

An off-chip piezoelectric stage was also required to actuate the MEMS-based cell puller of Serrell et al. (2007, 2008). Fig. 8 shows the microfabricated structure which was based on a circular platform split in two parts, one of them being movable. The latter, which was linked to the piezoelectric stage, could be translated along one direction with maximum travel range of $50 \mu \mathrm{m}$, a displacement resolution of $0.4 \mathrm{~nm}$ and a bandwidth of $520 \mathrm{~Hz}$. 


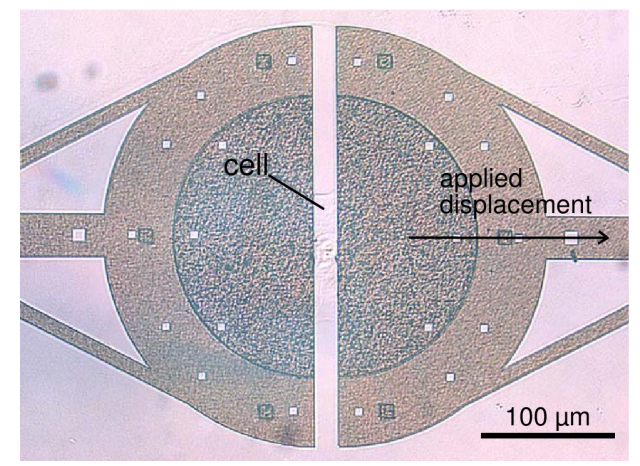

Figure 8: Close-up of a MEMS-based tensometer: an adherent cell anchored in the middle of a disk can be stretched via the translation of a movable part. Image adapted from (Serrell et al., 2007)

\section{MEMS for the mechanical stimulation of a small group of cells}

\subsection{Parallelized stimulation with an array of electromagnetic microactuators}

In Sniadecki et al. (2007, 2008), the authors fabricated, characterized and tested a dense bed of soft micropillars arranged in a pattern array. Spatial resolution of the array was $9 \mu \mathrm{m}$, whereas each pillar measured $1.5 \mu \mathrm{m}$ in radius, $10 \mu \mathrm{m}$ in height and had a low stiffness of $32 \mathrm{nN} / \mu \mathrm{m}$. With such dimensions, the investigators were able to provide local stimulation to adherent cells lying on the surface of the micropillars through the use of a horizontal uniform magnetic field. The latter was generated by external NdFeB magnets which controlled the bending of certain pillars (see Fig. 9). Indeed, magnetic cobalt nanowires 
(350 $\mathrm{nm}$ in diameter, 5-7 $\mu \mathrm{m}$ long) were incorporated within some pillars during the fabrication process of the array (1 nanowire per 200 pillars). Attracted magnetic wires enabled the bending of the magnetized pillars up to $15^{\circ}$ relative to the pillars' longitudinal axis. Such bending led to a pillar displacement ranging from $100 \mathrm{~nm}$ to $1 \mu \mathrm{m}$. For a cell positioned at the top of a magnetic pillar, this displacement transferred a punctual force to the focal adhesion sites of the cell. The magnitude of this force was a function of the pillar as well as the nanowire dimensions, in accordance with the following equation:

$$
F_{M a g}=\frac{3 \mu_{\perp} B\left(L+L_{W}\right)}{2\left(L^{2}+L_{W} L+L_{W}^{2}\right)}
$$

where $L$ and $L_{W}$ are the lengths of the post and the length of the embedded nanowire respectively, and $\mu_{\perp}$ is the component of the dipole moment perpendicular to the magnetic field $B$, as represented in the inset c) of Fig. 9.

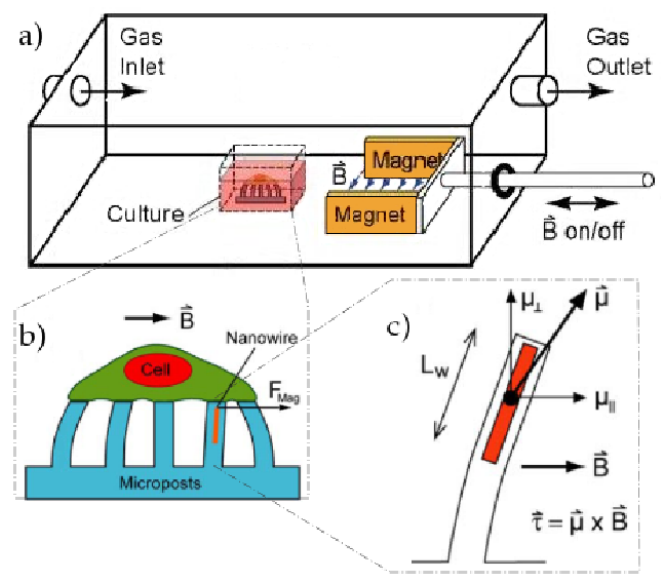

Figure 9: a) Experimental setup of Sniadecki et al. where permanent magnets generate a magnetic field surrounding a cell culture chamber. b) Close-up of the cell culture chamber: an adherent cell is lying on a bed of micropillars, one of them incorporating a magnetic nanowire. c) Parameters influencing the bending of a magnetic pillar in accordance with Equation (9). Drawings adapted from (Sniadecki et al., 2007, 2008) 
For a nanowire of length $L_{W}=5 \mu \mathrm{m}$, a magnetic field B of $0.31 \mathrm{~T}$ created a torque of $210 \mathrm{nN} / \mu \mathrm{m}$. During experiments, a maximum force of $27 \mathrm{nN}$ was validated by the authors. One may note that this work was originally intended for the local stimulation and study of individual mouse fibroblasts. However, and considering the simple structure adopted by the authors, we believe that such system could be further extended, and readily transposed to the stimulation of tens of cells.

\subsection{Parallelized stimulation with an array of microbeams actuated by positioning} stages

Sasoglu et al. $(2007,2008)$ manufactured a comparable array of compliant microposts for stretching axons of multiple neurons aligned in a regular pattern. Pillars were however larger, with a diameter of $40 \mu \mathrm{m}$, a length of $120 \mu \mathrm{m}$. The separation at the base of the pillars was also wider. As opposed to the device proposed by Sniadecki et al., this array was not intended to offer subcellular spatial resolution. Instead, each cell was attached to the free end of a pillar and could be entirely stretched. To control the bending of the micropillars, the authors favored a distant micromanipulation station (see Fig. 10) which offered a precision of $40 \mathrm{~nm}$. With this configuration, the authors claimed that tensile forces as small as $250+/-50 \mathrm{nN}$ and as great as $25+/-2.5 \mu \mathrm{N}$ could be exerted on the specimens under investigation.

\subsection{Parallelized stimulation with an array of Electro-Active Polymer (EAP)} microactuators

EAP are polymers that change in shape or size in response to an electrical stimulation. An array of $100 \times 100 \mu \mathrm{m}^{2}$ EAP microactuators was built by Ak- 


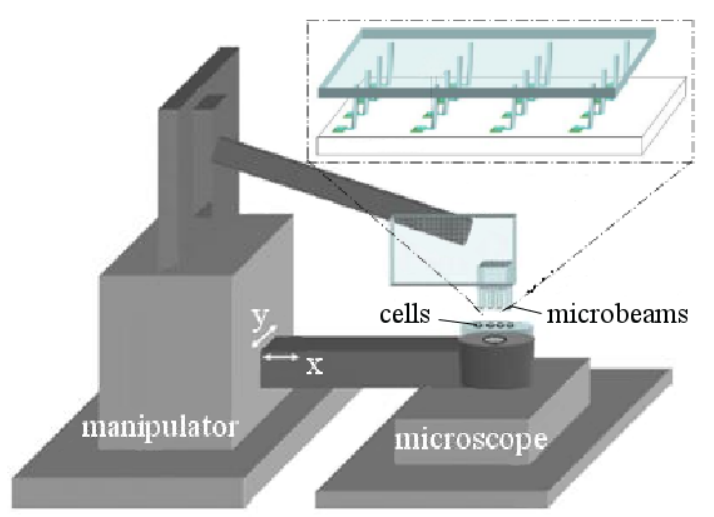

Figure 10: Concept of a micropost array where axons of tens of neurons can be stretched in parallel via the translation of a distant micropositioning stage. Drawings adapted from (Sasoglu et al., 2007, 2008)

bari et al. (2010) to perform the individual stretching of 128 cells. In this array (see Fig. 11), compliant gold electrodes (100 $\mu$ m wide) were deposited by low energy ion implantation on each side of a $30 \mu$ m thick, $30 \%$ pre-stretched, PDMS (polydimethylsiloxane) membrane. Next, the membrane was placed over a rigid PDMS support composed of $200 \mu \mathrm{m}$ wide channels. The membrane provided flexibility and could expand over the channels when high voltages were applied to the electrodes. This design permitted to restrict the stimulation areas to intersections between electrodes and channels. Although this technique was not applied to living cells, the investigators predict that each cell could potentially receive up to $10-20 \%$ uniaxial strains.

\section{MEMS for the mechanical stimulation of a large cell population}

The possibility to stimulate larger cell samples may be seen as a logical next step. In this section, we arbitrarily define that the actuation principles described hereafter can deal with a cell population including at least thousands of cells. The 


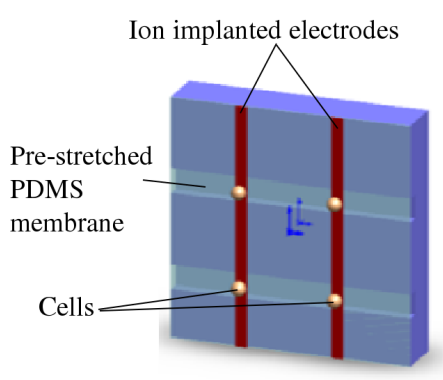

$0 \mathrm{~V}$

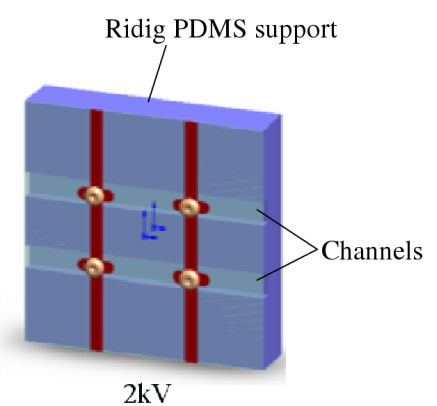

Figure 11: Concept of an array of EAP microactuators. Left: device at $0 \mathrm{~V}$ with four cells placed at the intersection between electrodes and channels. Right: device when high voltage $(2 \mathrm{kV})$ is applied; the four cells are stretched along the channels. Drawings adapted from (Akbari et al., 2010)

only objective of this minimum is to ensure a sufficient difference in the number of cells to be stimulated in order to guarantee that such large samples cannot be addressed by the limited throughput configurations presented in Section 3.

\subsection{Simultaneous stimulation}

Hereafter, we introduce some MEMS able to inherently stimulate very large amounts of cells concurrently. In order to do this, such MEMS directly stress entire cell populations.

\subsubsection{Simultaneous stimulation with cell substrate deformation}

Laboratory devices for the stretching of tissues or large cell populations cultured on thin compliant substrates served as initial tools to investigate the effects of mechanical cues on living cells (e.g., Norton et al., 1995; Sotoudeh et al., 1998; Clark et al., 2001; Pfister et al., 2003). This concept can be scaled down to the microscale level, and MEMS devoted to the distention of cell substrates have been actuated by electrostatic actuators (Wu et al., 2005), fluids (Kim et al., 2007), and air pressure (Sim et al., 2007; Tan et al., 2008; Moraes et al., 2010). 

the authors.

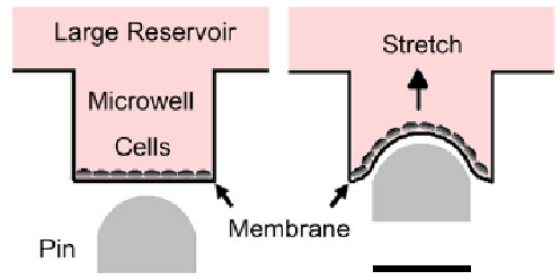

Figure 12: Bending and stretching of soft microwells via Braille display pins. Scale bar respresents $1.25 \mathrm{~mm}$ (Kamotani et al., 2008)

243

In (Kamotani et al., 2008), the authors designed a refreshable Braille display to individually bend up to 24 deformable microwells (see Fig. 12). Each well measured $1.7 \mathrm{~mm}$ in diameter, and the bottom was constituted of a PDMS membrane, with a Young's modulus approximately $750 \mathrm{kPa}$, a Poisson ratio's of 0.49 , and a thickness ranging between $100-200 \mu \mathrm{m}$. Cells to be stressed were directly cultured on the PDMS membranes, and the pins of the Braille display were piezoelectrically actuated. The frequency and duration of the stretching applied by each pin could be controlled via a computer. Maximum extension of the pins decreased from $0.7 \mathrm{~mm}$ for no load to $0.3 \mathrm{~mm}$ when the pins pushed a membrane $200 \mu \mathrm{m}$ thick. A pushing force of $0.18 \mathrm{~N}$ was experimentally validated by Membrane

(1)



ensuring a laminar flow with no turbulence within the microchannels. chip. Channel height was $25 \mu \mathrm{m}$ whereas channel width ranged from $250 \mu \mathrm{m}$ to $1000 \mu \mathrm{m}$. Such small dimensions guaranteed a low Reynolds number $(\operatorname{Re} \leq 1.0)$,

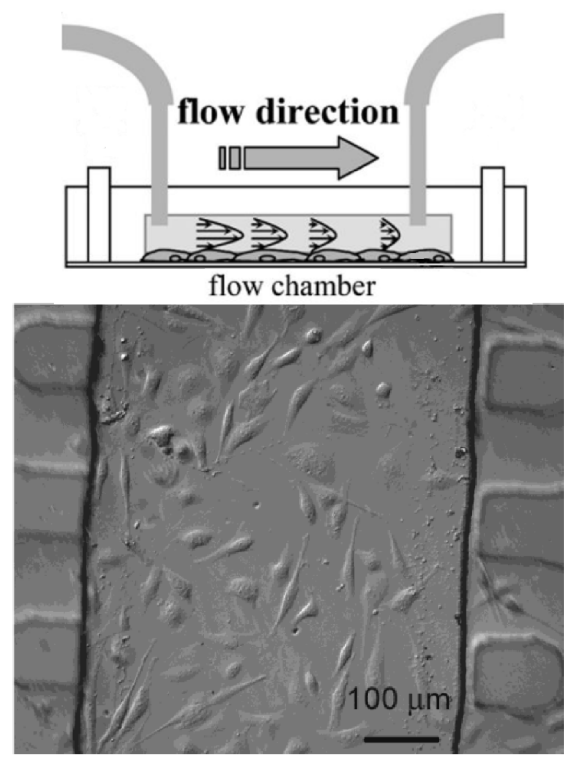

Figure 13: Top: sketch representing the principle of a microfluidic channel imposing shear stress to a culture of adherent cells (Tsou et al., 2008). Bottom: microscope view of fibroblasts cultured in one of a parallel-plate flow chambers. Average fibroblast diameter was about $20 \mu \mathrm{m}$ after attachment (Lu et al., 2004)

For a parallel-plate channel with an infinite aspect ratio, the generated wall shear stress can be expressed as:

$$
\tau_{w}=\left(\frac{6 \mu}{h^{2} w}\right) Q
$$


multiple shear stress conditions. This allowed the authors to mimic a variety of stresses that vascular cells naturally undergo in the vessel architecture of the arterial system. During experiments, shear stresses up to $4000 \mathrm{dyne} / \mathrm{cm}^{2}$ were generated by the authors

\subsection{Serial approaches for high throughput stimulation}

Serial approaches constitute an alternative option to stimulate thousands of cells. Hereafter, we introduce some MEMS able to stress isolated cells sequentially at high stimulation rates.

\subsubsection{Serial stimulation with constricted channels}

If fluids can naturally expose cells to shearing stresses, they can also be used to transport suspended cells toward excitation areas. In (Brody et al., 1995; Youn et al., 2008; Hou et al., 2009), suspended cells were serially guided toward synthetic lattices of constricted areas. This approach allowed Kim et al. (2009b) to mimic the segmental contractions undergone by bovine embryos in a oviduct. As shown in Fig. 14, compressive stresses occurred while the embryos traveled through the constricted areas (i.e., circular channels incorporating areas with a smaller inner diameter). For embryos with a diameter ranging approximately from 150 to $190 \mu \mathrm{m}$, the authors reported compressive forces up to $0.8 \mu \mathrm{N}$.

\subsubsection{Serial stimulation with optical stretchers $(O S)$ and electric fields}

In (Lai et al., 2008; Remmerbach et al., 2009; Lautenschläger et al., 2009), OS similar the one depicted in Fig. 3 were combined with microchannels. Fluid flows ensured the continuous and fast delivery of suspended cells toward the divergent laser beams emanating from the two optical fibers. Thereby, flowing cells could be trapped one by one. Variations of light intensity then allowed the 


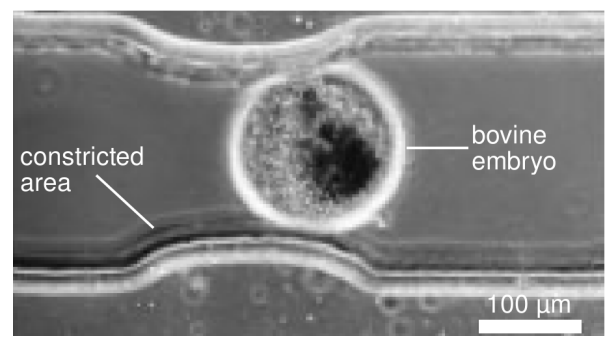

Figure 14: Microfluidic channel including a constrictive area. The image shows a bovine embryo being compressed while crossing the narrow section of the channel. Image adapted from (Kim et al., 2009b)

modulation of the amount of stretching applied to the trapped cell. In particular, stimulation rate up to to 100 cells/hour was reported with such an approach (Lincoln et al., 2007).

Similarly, microchannels have been associated with surrounding electric fields. In (Bao et al., 2008), electric field intensity was concentrated toward the narrow section of a microchannel (see Fig. 15). During experiments, field intensities of $200 \mathrm{~V} / \mathrm{cm}, 400 \mathrm{~V} / \mathrm{cm}$ as well as $600 \mathrm{~V} / \mathrm{cm}$ were applied. Stress indirectly arose from the electroporation phenomena. In effect, cells may open up pores when they experience an external electric field with an intensity beyond a certain threshold. Material exchange across the membrane may then occur. A direct consequence was the swelling of human breast epithelial cells while they were flowing through the microchannel. Even though the amount of stress induced was not explicitly quantified by the authors, such method allowed to strain suspended cells at stimulation rates as high as 5 cells/s. 


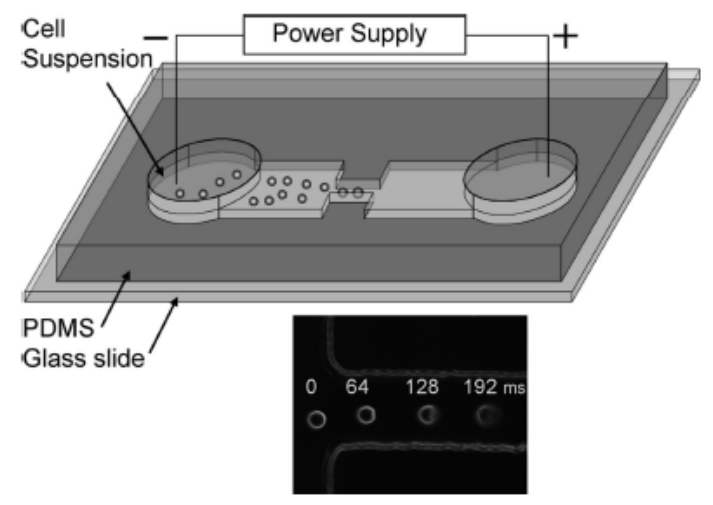

Figure 15: Top: electric fields used in conjunction with microfluidic channel to provoke cell electroporation. Inset: swelling evolution at different times for a cell experiencing electroporation while progressing through a microchannel (Bao et al., 2008)

\section{Mechanical stimulation of cells: discussion about the number of cells targeted}

On the basis of the details presented in the previous sections, the following questions might be legitimately asked: why aim to stimulating more than one cell? What are the differences between actuation systems targeting tens of cells and those targeting thousands of cells? Are the latter better simply because they can deal with a larger amount of cells? As a matter of fact, the answers to these questions are rather complex. Indeed, in the specific context of cell mechanostimulation, engineering specifications become intercorrelated to biological factors. Hereafter, we discuss some parts of the answers.

\subsection{Mechanical stimulation of a single cell: strengths and weaknesses}

The large variety of actuation methods that were summarized in Section 2 demonstrates that the stimulation of a single isolated cell has been largely addressed. Indeed, for different but complementary reasons, both life sciences and 
engineering communities have been highly involved in the development of systems able to interact with a single cell. Recent achievements in this enterprise have marked a milestone in cell mechanics. The possibility to interact with an individual cell has enabled tremendous breakthroughs by helping cell biologists to elucidate how a cell receives and processes extracellular mechanical signals.

A major advantage attributed to almost all devices of Section 2 is that both localization and magnitude of the stress applied upon a cell can be finely tuned. This is certainly a necessary condition to conduct successful experiments on living cells. On the other hand, one may highlight the fact that in most works cited, delicate and time-consuming steps are often required to properly place the cell prior to stimulation. For instance, in (Eppell et al., 2006; Shen et al., 2008), the authors used small drops of epoxy to attach a fibril between the two pads of their uniaxial cell tenser. It is reasonable to assume that such "gluing" chemicals may interact with the living cell, having a certain impact on the intrinsic cell mechanical properties.

It is important to note that cells are often considered as passive and homogeneous viscoelastic materials. In effect, such assumptions greatly simplify the modeling of living cells (Lim et al., 2006). In actuality, cells are highly anisotropic entities whose mechanical properties can evolve both in time and space over a variation of several orders of magnitude. Thereby, it has been experimentally observed that an identical mechanostimulus may actually engender variable cell mechanical responses from cell to cell, even within a given cell line. A more representative overview of the cellular behavior could be obtained by considering the averaged responses of many individual cells subjected to the same mechanical stress. A new tendency based on statistical studies has hence progressively emerged (see for instance Mizutani et al., 2008, Hiratsuka et al., 
2009). Unfortunately, MEMS of Section 2 do not ideally lend themselves to the fast stimulation of many cells since they usually involve long protocols aimed at properly preparing the cell prior to experiment (e.g., ensuring a sufficient attachment of the cell on functionalized probes), the stimulation of just a few cells may still take several hours.

\subsection{Mechanical stimulation of tens of cells: strengths and weaknesses}

To increase cell stimulation rate, arrays of microactuators have been developed to stimulate small groups of isolated cells, as seen in Section 3. Via the duplication of structures (e.g., microposts, microcantilevers) originally intended for the stimulation of an isolated cell, these devices try to preserve the initial advantages of single actuators. It is however worth noting that if individual access to each cell remains possible, actuators are usually not individually controlled. Although the possibility to independently control several groups of EAP actuators has been recently reported in (Akbari et al., 2010), the ability to individually tune the magnitude and localization of the stress applied upon each cell is often partly lost. However, the real shortcoming of these array configurations is relative to their lack of scalability.

Indeed, the duplication of perfectly identical structures at the microscale remains limited to a certain extent. Indeed, the fabrication of an array which would include thousands of microactuators still poses formidable challenges. This is representative of a technological gap. This limit is represented in Fig. 16, which also illustrates the fact that, in addition to technical complexity, large replication of patterns will usually induce a significant increase in cost. Thereby, and to the best of our knowledge, no array configuration can presently stimulate thousands 


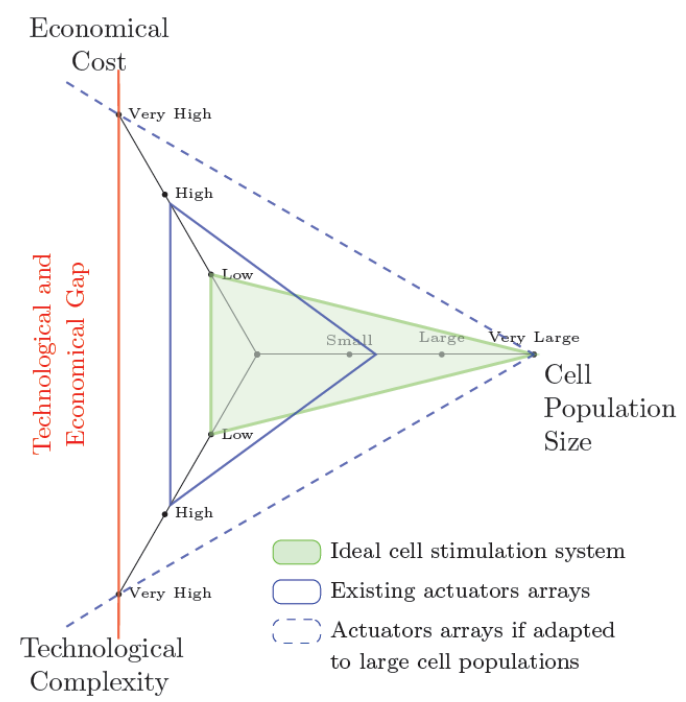

Figure 16: Prediction highlighting the limitation of current microactuators arrays (blue triangle): they cannot be easily transposed to the stimulation of very large cell populations. In contrast with an ideal stimulation system (green area), we indeed foresee that even the replication of simple repetitive patterns could not be indefinitely extended without drastic increase in both cost and technological complexity (dashed lines).

of isolated cells. Meanwhile, studies conducted on tens of cells may still appear as modest populations compared to the colossal number of cells that constitute a living organism.

\subsection{Mechanical stimulation of thousands of cells: strengths and weaknesses}

Alternative configurations targeting thousands of cells have also been developed. As presented in Section 4, the culture of a large population of adherent cells on a thin compliant substrate (see Fig. 12) can facilitate the transfer of mechanical stress to the whole cell population by simply distorting the substrate. While this approach permits the stimulation of a very large number of cells in a simple manner, several restrictions apply. Generally speaking, and independent 
of the type of actuator used to induce substrate deformation, stress distribution remains usually inhomogeneous. Indeed, depending on the Poisson's ratio of the material used, even if one stretches (or bends) the thin substrate solely along one dimension, coupling between radial and tangential strains occurs during substrate distention. Therefore, based on their position on the substrate, all cells are not subjected to the same amount of stress. Most importantly and unlike the matrix configuration of Section 3, the individual stimulation of a particular cell is completely lost.

To mitigate the latter restriction, configurations involving microchannels with fluid flows that allow the serial delivery of individual suspended cells toward excitation areas have also been explored. In particular, when coupled to laser beams or external electric fields, microfluidic chips such as the one of Fig. 15 offer the possibility to modulate the stress intensity applied upon each cell while also achieving relatively high stimulation rates. This paved the way for microsystems aimed at offering high throughput cell stimulation. Despite these remarkable advantages, these configurations work exclusively with suspended cells showing high degree of symmetry and/or high optical uniformity. Unfortunately, this excludes studies of adherent cells.

\section{Actuation means of MEMS for the mechanical stimulation of cells: com-} parative analysis

It is now clear that a large number of different actuation means are available for the mechanical stimulation of living cells. Among this wide variety, one might wonder if a ranking could be established comparing these technologies. In other words, is one actuation principle better than another? Which actuation 
type should be used in the design of a new MEMS intended to apply mechanical stimuli upon cells? In this section, we discuss some of relevant aspects of cell mechanostimulation that make it such a complex and delicate task.

\subsection{Notion of stress control}

During the mechanical excitation of living cells, an optimal actuation mean should offer a high degree of accuracy in the control of the physical constraint applied. Ultimately, it is critical to mimic the constraints faced by cells in vivo. Moreover, it is vital to avoid the generation of stress with improper orders of magnitude that could cause irreversible damages to living cells. The chart from Fig. 17 gives an overview of the inherent performances for each type of actuation mean and relates their respective resolutions both in terms of displacement and force.

Additionally, the orders of magnitude in the chart have been scaled according to relevant information and data collected from various sources. Therefore, our set of actuation techniques were not based purely on a restricted number of particular MEMS. For instance, performances of positioning stages have been evaluated based on the large panel of product references and datasheets available from manufacturers such as Physik Instrumente (PI). Likewise, lower and upper bounds fixing global performances of piezoelectric, electrostatic, as well as electrothermal microactuators have been extrapolated from (Bell et al., 2005; Hubbard et al., 2006; Naraghi et al., 2010). In order to accurately characterize the overall capabilities of each actuation technique, it is also essential to consider several cell studies conducted via experimental configurations. For air pressure, data have been extracted from (Hochmuth et al., 1993; Hochmuth, 2000; Chu et al., 2004; Sanchez et al., 2008). Values for fluid flows have been based on 


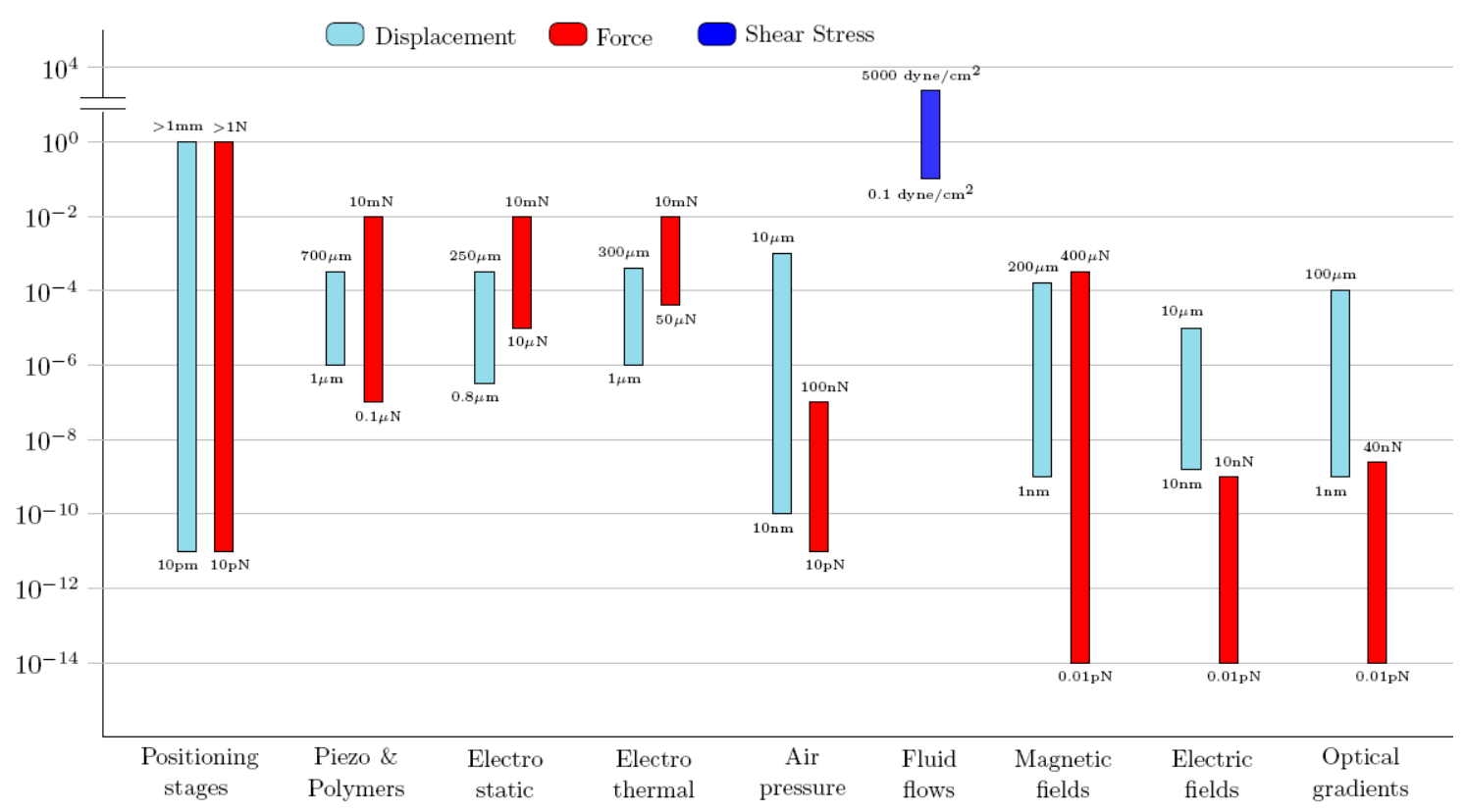

Figure 17: Bar graph evaluating the inherent performances of different actuation means that have been (or might be) found in MEMS for stressing living cells. Values reported here are not limited to the microdevices of this paper, but also take consideration of overall orders of magnitude found in several references (see text for further details)

(Bussolari et al., 1982; Usami et al., 1993; Malek et al., 1995; Cao et al., 1997; Blackman et al., 2000; Dong and Lei, 2000; Hsiai et al., 2002). For magnetic fields, displacement and force amplitudes have been averaged from the analysis of several magnetic tweezers (MT) setups (Evans et al., 1995; Bausch et al., 1998; Simson et al., 1998; Alenghat et al., 2000; Huang et al., 2005; GarciaWebb et al., 2007; Kollmannsberger and Fabry, 2007; Reed et al., 2008; Spero et al., 2008). Data for electric fields have been fixed according to (Engelhardt and Sackmann, 1988; Zimmermann et al., 2000; Zhang and Liu, 2008). Finally, information about optical gradients has been collected from several optical tweezers (OT) based assays (Hénon et al., 1999; Sleep et al., 1999; Dao et al., 2003; 


\subsection{Notion of size and functional density}

At the microscale, the volume of an actuator is a parameter that should not be ignored. Since many of the MEMS actuators presented in this paper can be scaled to different dimensions, an evaluative parameter able to neutralize those variations should be introduced in order to objectively compare different types of actuators. Such a parameter has for instance been proposed in (Carlen and Mastrangelo, 2002):

$$
P_{a}=\frac{F_{a} \epsilon_{a}}{V_{a}}
$$

In Fig. 17, positioning stages appear as the most advantageous mean to actuate MEMS. Indeed, they offer the versatility to combine large travel and force

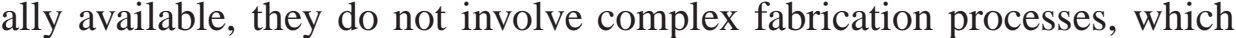
simplify their implementation. It is indisputable that displacement and quired since these features are not sufficient to fairly assess a set of actuation means. Hereafter, some additional specifications are discussed.

where $F_{a}, \epsilon_{a}$ and $V_{a}$ are the actuating force, the maximum displacement and the total volume of the actuator considered. By definition, $P_{a}$ represents the functional density (expressed in $J / \mathrm{m}^{3}$ ).

In the specific context of cell stimulation, one could try to relate $P_{a}$ to the number of cells that can be actuated by a single actuator. As discussed in Section 4.2.2, ideal microactuators could independently target a large number of isolated cells, in a minimal volume. Unfortunately, trying to express $P_{a}$ in such 
a way for various types of actuation principles is not an easy task. This is especially true in the case of contact-based approaches (i.e., cells are directly touched by the actuator's tip), where the quantity of cells that can be targeted directly depends on the type of end effector used. Therefore, a given translation stage could be indifferently linked to a single microcantilever or a matrix encompassing tens of cantilevers, such as the one reported in (Polesel-Maris et al., 2007).

Although we are aware of the fact that Equation (11) fails to take into account the number of samples that can be actuated by a given actuation mean, $P_{a}$ remains a valuable parameter to consider in our context (as for all types of MEMS). For instance, it allows one to confirm that the important volume of a commercial positioning stage will actually drastically limit its functional density. Presently, MEMS conceived for high throughput cell screening do not primarily aim at providing autonomous and portable devices. However, the low functional density offered by actuators such as positioning stages might limit further progress in the development of future MEMS for cell mechanics. Conversely, on-chip microactuators (e.g., electrothermal, electrostatic actuators) showing high functional density may unlock some of the technological gaps currently encountered.

\subsection{Notion of biocompatibility}

Actuators intended to mechanically stimulate biological cells must deal with additional constraints. Thereby, it appears essential to conserve cells in specific solutions during manipulation. Indeed, cell medium allows the continuous delivery of vital nutrients in order to maintain cells alive. Meanwhile, the performance validated in ambient conditions for some actuators may be significantly altered in the presence of liquids.

This is the case for electrostatic comb drives, such as the one in Fig. 6. Due 
to the hydrophobic nature of the silicon-water interface, intricate phenomena such as air trapping between the comb drive teeth and the MEMS ground plane may arise. Furthermore, the enhanced electrical conductivity of liquids usually reduce their initial stroke.

Likewise, electrothermal microactuators also cope with challenging phenomena when they are plunged in a liquid environment. For instance, Zhang et al. (2008) underlined the fact that continuous power supply of the device shown in Fig. 5 proves to be unsuitable for underwater operation due to electrolysis. Although alternating voltages allowed the authors to operate their actuator in electrolytic solution, its initial travel range of $9 \mu \mathrm{m}$ measured in air was restricted to $4 \mu \mathrm{m}$ in liquids. An additional feature of electrothermal actuators relates to the high temperature that they can reach during operation. Since cells are particularly sensitive to temperature fluctuations, high temperatures may potentially cause irreversible damages. Special precautions should hence be taken accordingly.

This remark might be extended to all types of contact-based actuation means. For instance, in (Boukallel et al., 2009), the authors avoid the use of conventional cantilevers with sharp tip (i.e., such as the ones used for conventional AFM), since the latter could cause damage to external lipid biomembranes during the loading of cells. Regardless of the shape of the mechanical extremity used, contamination may occur once the tool touches the cell. Therefore, the tips should be properly cleaned before each new experiment. This additional laborious step may however prevent repetitive analysis.

Non-contact actuation techniques would allow to circumvent such a restriction. For example, electric fields generated by microfield cages such as the one presented in Fig.2 stretch cells without touching them. However, electric fields 
can directly affect cells under test (Voldman, 2006). Although no direct contact occurs during stimulation, electric fields cause power dissipation in the form of Joules heating in a conductive medium. Therefore, and as in the case of electrothermal actuators, the usage of electric fields requires to monitor changes in temperature that can affect the phenotype of cells.

Alternatively, suspended cells can also be stretched without contact with optical gradients. Nonetheless, it is admitted that highly concentrated laser beams used in conventional optical tweezers (OT) may be hazardous for cells (Knig et al., 1996; Liang et al., 1996; Neuman et al., 1999; Peterman et al., 2003). Introduced in Section 2.3, OS made of two optical fibers avoids this problem by reducing the light intensity transmitted to the cell of interest. Indeed, divergent laser beams that stretch the cell are necessarily unfocused, limiting the risk of radiation damage. Consequently, high power lasers can be used without damaging the cell. Unfortunately, to date, OS were only proven to be suitable for the stimulation of cells showing a high degree of symmetry and a uniform optical density.

Comparatively, MT (see Fig.1) are nowadays considered safe for cells. Indeed, magnetic fields do not significantly disturb or affect the cell response upon short times of exposure required for the application of a mechanical stimulus. Despite this appealing advantage, several restrictions are usually associated with these types of configurations. First, if MT offer the possibility to remotely control magnetic microbeads locally attached to a cell membrane, the magnetic forces applied on the microbeads strongly depends on the beads' size. Meanwhile, it may be difficult to avoid size variations from bead to bead in experimental conditions. Likewise, material properties of the beads used (e.g., magnetic moment) cannot be easily controlled and may hence influence the amount of force gener- 
ated by a given surrounding magnetic field upon the microparticles. Moreover, the adhesion procedure of the beads remains an unpredictable process. By definition the position of the binding sites as well as the number of magnetic particles adhering to a cell membrane cannot be accurately defined. Accordingly, formation of bead aggregates may appear. Additionally, since bead immersion is unpredictable, the force distribution around adhesion sites can actually be highly heterogeneous.

According to our comparative analysis, no actuation mean may be clearly considered as ideal. Indeed, each actuation method have its own strengths and weaknesses. Accordingly, selection of an appropriate actuator appears mostly possible based on a trade-off related to the type of cell investigations that have to be carried out. To sum up this complexity, we propose two charts in Fig.18 for further evaluation between contact and non-contact actuation types. In these charts, desired aspects of key properties required in the specific context of cell stimulation are reported at the extremity of each axis. In consequence, pentagons covering larger surfaces should theoretically represent most appropriate techniques. We however highlight the fact that these charts incorporate criteria that are difficult to objectively estimate. For instance, scientific evidences allowing to quantitatively evaluate the risk of side effects caused by a given actuation technique remain complex to collect. Therefore, criteria reported have been qualitatively ranked based on authors' personal opinions. Nevertheless, and despite their qualitative nature, we believe that these factors remain relevant and should absolutely be considered before selection of an actuation technique. 
Known Side

Effects on Cells

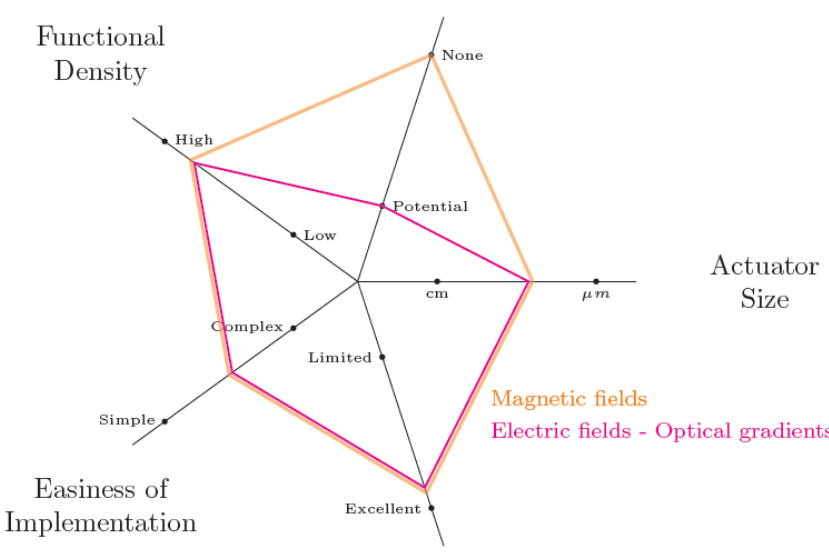

Cell Medium

Compatibility
Known Side

Effects on Cells

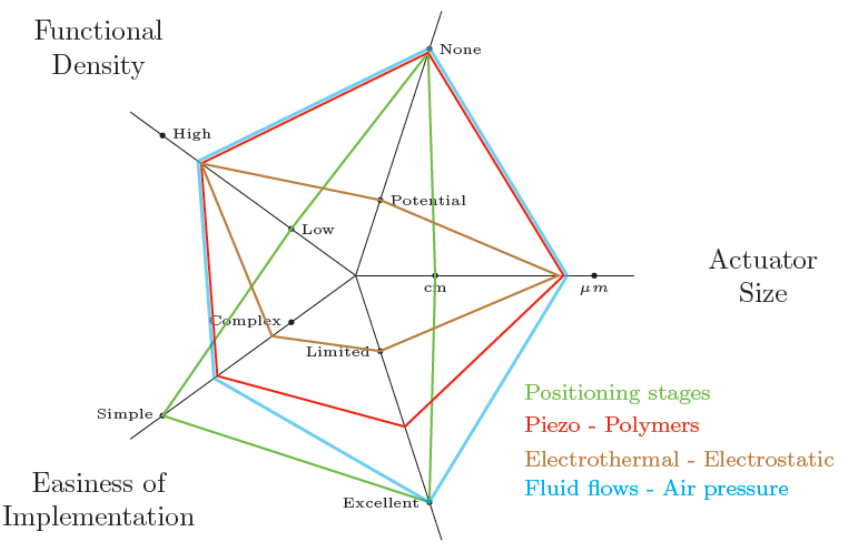

Cell Medium Compatibility

Figure 18: Additional criteria considered for further comparison of the actuation means found in MEMS dedicated to cell stimulation. Functional Density corresponds to $P_{a}$ as defined in Equation (11). It complements the notion of Actuator Size by relating the volume with the stress control accuracy that can be achieved by a given actuation technique. Cell Medium Compatibility refers the capability of each technique to operate in liquids. From a physical principle, the criterion Easiness of Implementation tries to consider the complexity and numbers of processes needed to obtain a functional actuator. Techniques that are known to induce effects on cell phenotype are distinguished in the branch Known Side Effects on Cells.

\section{Concluding remarks}

This paper reports the majority of actuation means currently used in MEMS for the mechanical stimulation of living cells. Additionally, we classify actuation means as a function relative to the amount of cells that they could potentially target. This allowed us to realize that the stimulation of single cells has already been largely addressed. Indeed, many different actuation means have already allowed to accurately stress isolated cells. However, a recent trend aiming at stimulating large amounts of cells emanates from the literature. This trend is mainly justified 
by the fact that, beyond the technological breakthroughs discovered at the single cell level, new applications require large amounts of isolated cells to perform statistical analyses and result in a better understanding of the cell behavior.

To date, parallel and serial cell stimulations remain commonly used by the research community. We discussed both approaches, and evaluated different types of actuators. It is interesting to notice that relatively high stimulation rates were achieved using the serial approach which involves optical gradients or electric fields combined with microfluidic channels. However, such configurations are efficient with restrictive types of suspended cells. To our knowledge, stimulation rate of adherent cells remains low, even though most cells are anchored to the extracellular matrix in vivo, and hence might be in a sense considered as physiologically more relevant. As a matter of fact, the individual stimulation of adherent cells in a high throughput manner remain presently challenging, and still need to be further addressed.

\section{Acknowledgments}

The authors would like to thank Nicholas Kettenhofen for his assistance in the writing of the paper.

\section{Conflict of Interest Statement}

As a condition for publication and/or participation in the reviewing process, we, Denis Desmaële, Mehdi Boukallel and Stephane Regnier, declare that we have no proprietary, financial, professional or other personal interest of any nature or kind in any product, service and/or company that could be construed as influencing the position presented in this manuscript. 
Addae-Mensah, K.A., Wikswo, J.P., 2008. Measurement techniques for cellular biomechanics in vitro. Experimental Biology and Medecine 233, 792-809.

Akbari, S., Niklaus, M., Shea, H., 2010. Arrays of EAP micro-actuators for single-cell stretching applications, in: Bar-Cohen, Y. (Ed.), Electroactive Polymer Actuators and Devices (EAPAD), SPIE. p. $76420 \mathrm{H}$.

Alenghat, F.J., Fabry, B., Tsai, K.Y., Goldmann, W.H., Ingber, D.E., 2000. Analysis of cell mechanics in single vinculin-deficient cells using a magnetic tweezer. Biochemical and Biophysical Research Communications 277, 93-99.

Ashkin, A., 1970. Acceleration and trapping of particles by radiation pressure. Physical Review Letters 24, 156-159.

Bao, G., Suresh, S., 2003. Cell and molecular mechanics of biological materials. Nature Materials 2,715-725.

Bao, N., Zhan, Y., Lu, C., 2008. Microfluidic electroporative flow cytometry for studying singlecell biomechanics. Analytical Chemistry 80, 7714-7719.

Bausch, A.R., Ziemann, F., Boulbitch, A.A., Jacobson, K., Sackmann, E., 1998. Local measurements of viscoelastic parameters of adherent cell surfaces by magnetic bead microrheometry. Biophysical Journal 75, 2038-2049.

Bell, D.J., Lu, T.J., Fleck, N.A., Spearing, S.M., 2005. MEMS actuators and sensors: observations on their performance and selection for purpose. Journal of Micromechanics and Microengineering 15, S153-S164.

Blackman, B.R., Barbee, K.A., Thibault, L.E., 2000. In vitro cell shearing device to investigate the dynamic response of cells in a controlled hydrodynamic environment. Annals of Biomedical Engineering 28, 363-372.

Boukallel, M., Girot, M., Régnier, S., 2009. Characterization of cellular mechanical behavior at the microscale level by a hybrid force sensing device. Journal of the Mechanical Behavior of Biomedical Material 2, 297-304.

Brody, J.P., Han, Y., Austin, R.H., Bitensky, M., 1995. Deformation and flow of red blood cells in a synthetic lattice: evidence for an active cytoskeleton. Biophysical Journal 68, 2224-2232.

Brown, T.D., 2000. Techniques for mechanical stimulation of cells in vitro: a review. Journal of Biomechanics 33, 3-14.

Bussolari, S.R., Dewey Jr, C.F., Gimbrone Jr, M.A., 1982. Apparatus for subjecting living cells 
to fluid shear stress. Review of Scientific Instruments 53, 1851-1854.

Cao, J., Usami, S., Dong, C., 1997. Development of a side-view chamber for studying cellsurface adhesion under flow conditions. Annals of Biomedical Engineering 25, 573-580.

Carlen, E.T., Mastrangelo, C.H., 2002. Electrothermally activated paraffin microactuators. Journal of Microelectromechanical Systems 11, 165-174.

Chan, B.P., Li, C., Au-Yeung, K.L., Sze, K.Y., Ngan, A.H.W., 2008. A microplate compression method for elastic modulus measurement of soft and viscoelastic collagen microspheres. Annals of Biomedical Engineering 36, 1254-1267.

Chiou, C.H., Huang, Y.Y., Chiang, M.H., Lee, H.H., Lee, G.B., 2006. New magnetic tweezers for investigation of the mechanical properties of single DNA molecules. Nanotechnology 17, $1217-1224$

Christopher, G.F., Yoo, J.M., Dagalakis, N., Hudson, S.D., Migler, K.B., 2010. Development of a MEMS based dynamic rheometer. Lab Chip 10, 2749-2757.

Chu, Y.S., Thomas, W.A., Eder, O., Pincet, F., Perez, E., Thiery, J.P., Dufour, S.F., 2004. Force measurements in E-cadherin-mediated cell doublets reveal rapid adhesion strengthened by actin cytoskeleton remodeling through Rac and Cdc42. Journal of Cell Biology 167, 11831194.

Clark, C.B., Burkholder, T.J., Frangos, J.A., 2001. Uniaxial strain system to investigate strain rate regulation in vitro. Review of Scientific Instruments 72, 2415-2422.

Constable, A., Kim, J., Mervis, J., Zarinetchi, F., Prentiss, M., 1993. Demonstration of a fiberoptical light-force trap. Optics letters 18, 1867-1869.

Crick, F.H.C., Hughes, A.F.W., 1950. The physical properties of cytoplasm: A study of the magnetic particle method part I, Experimental. Experimental Cell Research 1, 37-80.

Cross, S.E., Jin, Y.S., Tondre, J., Wong, R., Rao, J.Y., Gimzewski, J.K., 2008. AFM-based analysis of human metastatic cancer cells. Nanotechnology 19, 384003 (8pp).

Dao, M., Lim, C.T., Suresh, S., 2003. Mechanics of the human red blood cell deformed by optical tweezers. Journal of the Mechanics and Physics of Solids 51, 2259-2280.

Desprat, N., Guiroy, A., Asnacios, A., 2006. Microplates-based rheometer for a single living cell. Sensors and Actuators B: Chemical 77, 05511 (1-9).

Dimova, R., Riske, K.A., Aranda, S., Bezlyepkina, N., Knorr, R.L., Lipowsky, R., 2007. Giant vesicles in electric fields. Soft Matter 3, 817-827. 
Dong, C., Lei, X.X., 2000. Biomechanics of cell rolling: shear flow, cell-surface adhesion, and cell deformability. Journal of Biomechanics 33, 35-43.

Engelhardt, H., Sackmann, E., 1988. On the measurement of shear elastic moduli and viscosities of erythrocyte plasma membranes by transient deformation in high frequency electric fields. Biophysical Journal 54, 495-508.

Eppell, S.J., Smith, B.N., Kahn, H., Ballarini, R., 2006. Nano measurements with micro-devices: mechanical properties of hydrated collagen fibrils. Journal of the Royal Society Interface 3, $117-121$.

Espinosa, H.D., Zhu, Y., Moldovan, N., 2007. Design and operation of a MEMS-based material testing system for nanomechanical characterization. Journal of Microelectromechanical Systems 16, 1219-1231.

Evans, E., Ritchie, K., Merkel, R., 1995. Sensitive force technique to probe molecular adhesion and structural linkages at biological interfaces. Biophysical Journal 68, 2580-2587.

Evans, E., Yeung, A., 1989. Apparent viscosity and cortical tension of blood granulocytes determined bu micropipet aspiration. Biophysical Journal 56, 151-160.

Fernández, P., Pullarkat, P.A., Ott, A., 2006. A master relation defines the nonlinear viscoelasticity of single fibroblasts. Biophysical journal 90, 3796-3805.

Furukawa, K.S., Ushida, T., Nagase, T., Nakamigawa, H., Noguchi, T., Tamaki, T., Tanaka, J., Tateishi, T., 2001. Quantitative analysis of cell detachment by shear stress. Materials Science and Engineering: C 17, 55-58.

Garcia-Webb, M.G., Taberner, A.J., Hogan, N.C., Hunter, I.W., 2007. A modular instrument for exploring the mechanics of cardiac myocytes. American Journal of Physiology - Heart and Circulatory Physiology 293, H866-H874.

Geitmann, A., 2006. Experimental approaches used to quantify physical parameters at cellular and subcellular levels. American Journal of Botany 93, 1380-1390.

Girbau, D., Lázaro, A., Pradell, L., 2003. RF MEMS switches based on the buckled-beam thermal actuator, in: 33rd European Microwave Conference, pp. 651-654.

Gladilin, E., Micoulet, A., Hosseini, B., Rohr, K., Spatz, J., Eils, R., 2007. 3D finite element analysis of uniaxial cell stretching: from image to insight. Physical Biology 4, 104-113.

Guck, J., Ananthakrishnan, R., Cunningham, C.C., Käs, J., 2002. Stretching biological cells with light. Journal of Physics: Condensed Matter 14, 4843-4856. 
Guck, J., Ananthakrishnan, R., Mahmood, H., Moon, T.J., Cunningham, C.C., 2001. The optical stretcher: a novel laser tool to micromanipulate cells. Biophysical Journal 81, 767-784.

Guido, I., Jaeger, M., Duschl, C., 2010. Dielectrophoretic stretching of cells allows for characterization of their mechanical properties. European Biophysics Journal , 1-810.1007/s00249010-0646-3.

Hénon, S., Lenormand, G., Richert, A., Gallet, F., 1999. A new determination of the shear modulus of the human erythrocyte membrane using optical tweezers. Biophysical Journal 76, 1145-1151.

Hiratsuka, S., Mizutani, T., Tsuchiya, M., Kawahara, K., Tokumoto, H., Okajima, T., 2009. The number distribution of complex shear modulus of single cells measured by atomic force microscopy. Ultramicroscopy 109, 937-941.

Hochmuth, R.M., 2000. Micropipette aspiration of living cells. Journal of Biomechanics 33, $15-22$.

Hochmuth, R.M., Ting-Beall, H.P., Beaty, B.B., Needham, D., Tran-Son-Tay, R., 1993. Viscosity of passive human neutrophils undergoing small deformations. Biophysical Journal 64, 15961601.

Hoffman, B.D., Crocker, J.C., 2009. Cell mechanics: Dissecting the physical responses of cells to force. Annual Review of Biomedical Engineering 11, 259-288.

Hou, H.W., Li, Q.S., Lee, G.Y.H., Kumar, A.P., Ong, C.N., Lim, C.T., 2009. Deformability study of breast cancer cells using microfluidics. Biomedical microdevices 11, 557-564.

Hsiai, T.K., Cho, S.K., Honda, H.M., Hama, S., Navab, M., Demer, L.L., Ho, C.M., 2002. Endothelial cell dynamics under pulsating flows: significance of high versus low shear stress slew rates. Annual Review of Biomedical Engineering 30, 646-656.

Huang, H., Kamm, R.D., Lee, R.T., 2004. Cell mechanics and mechanotransduction: pathways, probes, and physiology. American Journal of Physiology - Cell Physiology 287, C1-C11.

Huang, H., Sylvan, J., Jonas, M., Barresi, R., So, P.T.C., Campbell, K.P., Lee, R.T., 2005. Cell stiffness and receptors: evidence for cytoskeletal subnetworks. American Journal of Physiology- Cell Physiology 288, 72-80.

Hubbard, N.B., Culpepper, M.L., Howell, L.L., 2006. Actuators for micropositioners and nanopositioners. Applied Mechanics Reviews 59, 324-334.

Janmey, P.A., McCulloch, C.A., 2007. Cell mechanics: integrating cell responses to mechanical 
stimuli. Annual Review of Biomedical Engineering 9, 1-34.

Kahn, H., Ballarini, R., Mullen, R.L., Heuer, A.H., 1999. Electrostatically actuated failure of microfabricated polysilicon fracture mechanics specimens. Proceedings of the Royal Society A $455,3807-3823$.

Kamotani, Y., Bersano-Begey, T., Kato, N., Tung, Y.C., Huh, D., Song, J.W., Takayama, S., 2008. Individually programmable cell stretching microwell arrays actuated by a braille display. Biomaterials 29, 2646-2655.

Kanger, J., Subramaniam, V., van Driel, R., 2008. Intracellular manipulation of chromatin using magnetic nanoparticles. Chromosome Research 16, 511-522.

Kim, D.H., KinWong, P., Park, J., Levchenko, A., Sun, Y., 2009a. Microengineered platforms for cell mechanobiology. Annual Review of Biomedical Engineering 11, 203-233.

Kim, M.S., Bae, C.Y., Wee, G., Han, Y.M., Park, J.K., 2009b. A microfluidic in vitro cultivation system for mechanical stimulation of bovine embryos. Electrophoresis 30, 3276-3282.

Kim, Y.C., Kang, J.H., Park, S.J., Yoon, E.S., Park, J.K., 2007. Microfluidic biomechanical device for compressive cell stimulation and lysis. Sensors and Actuators B: Chemical 128, $108-116$.

Kiuchi, M., Matsui, S., Isono, Y., 2007. Mechanical characteristics of FIB deposited carbon nanowires using an electrostatic actuated nano tensile testing device. Journal of Microelectromechanical Systems 16, 191-201.

Koay, E.J., Shieh, A.C., Athanasiou, K.A., 2003. Creep indentation of single cells. Journal of Biomechanical Engineering 125, 334.

Kollmannsberger, P., Fabry, B., 2007. High-force magnetic tweezers with force feedback for biological applications. Review of Scientific Instruments 78, 114301 (1-6).

Korlach, J., Reichle, C., Müller, T., Schnelle, T., Webb, W.W., 2005. Trapping deformation and rotation of giant unilamellar vesicles in octode dielectrophoretic field cages. Biophysical Journal 89, 554-562.

Kushkiev, I., Jupina, M.A., 2005. Modeling the thermo-mechanical behavior of a V-shaped composite buckle-beam thermal actuator, in: COMSOL Multiphysics User's Conference, Boston.

Knig, K., Liang, H., Berns, M.W., Tromberg, B.J., 1996. Cell damage in near-infrared multimode optical traps as a result of multiphoton absorption. Optics Letters 21, 1090-1092.

Lai, C.W., Hsiung, S.K., Yeh, C.L., Chiou, A., Lee, G.B., 2008. A cell delivery and pre- 
positioning system utilizing microfluidic devices for dual-beam optical trap-and-stretch. Sensors and Actuators B: Chemical 135, 388-397.

Lautenschläger, F., Paschke, S., Schinkinger, S., Bruel, A., Beil, M., Guck, J., 2009. The regulatory role of cell mechanics for migration of differentiating myeloid cells. Proceedings of the National Academy of Sciences 106, 15696.

Lee, G.Y.H., Lim, C.T., 2007. Biomechanics approaches to studying human diseases. Trends in Biotechnology 25, 111-118.

Lekka, M., Laidler, P., Gil, D., Lekki, J., Stachura, Z., Hrynkiewicz, A.Z., 1999. Elasticity of normal and cancerous human bladder cells studied by scanning force microscopy. European Biophysics Journal 28, 312-316.

Lele, T.P., Sero, J.E., Matthews, B.D., Kumar, S., Xia, S., Montoya-Zavala, M., Polte, T., Overby, D., Wang, N., Ingber, D.E., 2007. Tools to study cell mechanics and mechanotransduction. Methods in Cell Biology 83, 443.

Li, Q.S., Lee, G.Y.H., Ong, C.N., Lim, C.T., 2008. AFM indentation study of breast cancer cells. Biochemical and biophysical research communications 374, 609-613.

Li, Y., Wen, C., Xie, H., Ye, A. an Yin, Y., 2009. Mechanical property analysis of stored red blood cell using optical tweezers. Colloids and Surfaces B: Biointerfaces 70, 169-173.

Liang, H., Vu, K.T., Krishnan, P., Trang, T. C. Shin, D., Kimel, S., Berns, M.W., 1996. Wavelength dependence of cell cloning efficiency after optical trapping. Biophysical Journal 70, $1529-1533$.

Lim, C.T., Dao, M., Suresh, S., Sow, C.H., Chew, K.T., 2004. Large deformation of living cells using laser traps. Acta Materialia 52, 1837-1845.

Lim, C.T., Zhou, E.H., Quek, S.T., 2006. Mechanical models for living cells - a review. Journal of Biomechanics 39, 195-216.

Lincoln, B., Schinkinger, S., Travis, K., Wottawah, F., Ebert, S., Sauer, F., Guck, J., 2007. Reconfigurable microfluidic integration of a dual-beam laser trap with biomedical applications. Biomedical Microdevices 9, 703-710.

Loh, O., A., V., Espinosa, H.D., 2009. The potential of MEMS for advancing experiments and modeling in cell mechanics. Experimental Mechanics 49, 105-124.

Lu, H., Koo, L.Y., Wang, W.M., Lauffenburger, D.A., Griffith, L.G., Jensen, K.F., 2004. Microfluidic shear devices for quantitative analysis of cell adhesion. Analytical Chemistry 76, 
5257-5264.

Lu, S., Guo, Z., Ding, W., Ruoff, R.S., 2006. Analysis of microelectromechanical system testing stage for tensile loading of nanostructures. Review of Scientific Instruments 77, 056103 (1-4).

MacQueen, L.A., Thibault, M.M., Buschmann, M.D., Wertheimer, M.R., 2010. Electrodeformation of individual mammalian cells in suspension, in: 10th IEEE International Conference on Solid Dielectrics (ICSD), Postdam, Germany. pp. 1-4.

Malek, A.M., Ahlquist, R., Gibbons, G.H., Dzau, V.J., Izumo, S., 1995. A cone-plate apparatus for the in vitro biochemical and molecular analysis of the effect of shear stress on adherent cells. Methods in Cell Science 17, 165-176.

Miyazaki, H., Hasegawa, Y., Hayashi, K., 2000. A newly designed tensile tester for cells and its application to fibroblasts. Journal of Biomechanics 33, 97-104.

Mizutani, Y., Tsuchiya, M., Hiratsuka, S., Kawahara, K., 2008. Elasticity of living cells on a microarray during the early stages of adhesion measured by atomic force microscopy. Japanese Journal of Applied Physics 47, 6177-6180.

Moraes, C., Chen, J.H., Sun, Y., Simmons, C.A., 2010. Microfabricated arrays for highthroughput screening of cellular response to cyclic substrate deformation. Lab Chip 10, 227234.

Naraghi, M., Chasiotis, I., 2009. Optimization of comb-driven devices for mechanical testing of polymeric nanofibers subjected to large deformations. Journal of Micromechanical Systems $18,1032-1046$.

Naraghi, M., Ozkan, T., Chasiotis, I., Hazra, S.S., de Boer, M.P., 2010. MEMS platform for on-chip nanomechanical experiments with strong and ductile nanofibers. Journal of Micromechanics and Microengineering 20, 125022 (9pp).

Neuman, K.C., Chadd, E.H., Liou, G. F. Bergman, K., Block, S.M., 1999. Characterization of photodamage to Escherichia coli in optical traps. Biophysical Journal 77, 2856-2863.

Norman, J.J., Mukundan, V., Bernstein, D., Pruitt, B.L., 2008. Microsystems for biomechanical measurements. Pediatric Research 63, 576.

Norton, L.A., Andersen, K.L., Arenholt-Bindslev, D., Andersen, L., Melsen, B., 1995. A methodical study of shape changes in human oral cells perturbed by a simulated orthodontic strain in vitro. Archives of Oral Biology 40, 863-872.

Peeters, E.A.G., Oomens, C.W.J., Bouten, C.V.C., Bader, D.L., Baaijens, F.P.T., 2005. Mechani- 
cal and failure properties of single attached cells under compression. Journal of biomechanics $38,1685-1693$.

Peterman, E.J.G., Gittes, F., Schmidt, C.F., 2003. Laser-induced heating in optical traps. Biophysical Journal 84, 1308-1316.

Pfister, B.J., Weihs, T.P., Betenbaugh, M., Bao, G., 2003. An in vitro uniaxial stretch model for axonal injury. Annals of Biomedical Engineering 31, 589-598.

Pillarisetti, A., Keefer, C., Desai, J.P., 2008. Mechanical characterization of fixed undifferentiated and differentiating mESC, in: 2nd IEEE RAS \& EMBS International Conference on Biomedical Robotics and Biomechatronics, USA. pp. 618-623.

Polesel-Maris, J., Aeschimann, L., Meister, A., Ischer, R., Bernard, E., Akiyama, T., Giazzon, M., Niedermann, P., Staufer, U., Pugin, R., et al., 2007. Piezoresistive cantilever array for life sciences applications, in: Journal of Physics: Conference Series, pp. 955-959.

Reed, J., Frank, M., Troke, J.J., Schmit, J., Han, S., Teitell, M.A., Gimzewski, J.K., 2008. High throughput cell nanomechanics with mechanical imaging interferometry. Nanotechnology 19 , 235101.

Remmerbach, T.W., Wottawah, F., Dietrich, J., Lincoln, B., Wittekind, C., Guck, J., 2009. Oral cancer diagnosis by mechanical phenotyping. Cancer research 69, 1728.

van der Rijt, J.A.J., van der Werf, K.O., Bennink, M.L., Dijkstra, P.J., Feijen, J., 2006. Micromechanical testing of individual collagen fibrils. Macromolecular bioscience 6, 697-702.

Riske, K.A., Dimova, R., 2006. Electric pulses induce cylindrical deformations on giant vesicles in salt solutions. Biophysical journal 91, 1778-1786.

Sanchez, D., Johnson, N., Li, C., Novak, P., Rheinlaender, J., Zhang, Y., Anand, U., Anand, P., Gorelik, J., Frolenkov, G.I., Benham, C., Lab, M., Ostanin, V.P., Schaffer, T.E., Klenerman, D., Korchev, Y.E., 2008. Non-contact measurement of the local mechanical properties of living cells using pressure applied via a pipette. Biophysical Journal 95, 3017-3027.

Sasoglu, F.M., Bohl, A.J., Allen, K.B., Layton, B.E., 2008. Parallel force measurement with a polymeric microbeam array using an optical microscope and micromanipulator. Computer Methos and Programs in Biomedicine 93, 1-8.

Sasoglu, F.M., Bohl, A.J., Layton, B.E., 2007. Design and microfabrication of a high-aspect-ratio PDMS microbeam array for parallel nanonewton force measurement and protein printing. Journal of Micromechanics and Microengineering 17, 623-632. 
Sato, K., Adachi, T., Ueda, D., Hojo, M., Tomita, Y., 2007. Measurement of local strain on cell membrane at initiation point of calcium signaling. Journal of Biomechanics 40, 1246-1255.

Sato, M., Theret, D.P., Wheeler, L., Ohshima, N., Nerem, R.M., 1990. Application of the micropipette technique to the measurement of cultured porcine aortic endothelial cell viscoelastic properties. Journal of Biomechanical Engineering 112, 263-268.

Scuor, N., Gallina, P., Panchawagh, H.V., Mahajan, R.L., Sbaizero, O., Sergo, V., 2006. Design of a novel MEMS platform for the biaxial stimulation of living cells. Biomedical Microdevices 8, 239-246.

Sen, S., Kumar, S., 2010. Combining mechanical and optical approaches to dissect cellular mechanobiology. Journal of Biomechanics 43, 45-54.

Serrell, D.B., Law, J., Slifka, A.J., Mahajan, R.L., Finch, D.S., 2008. A uniaxial bioMEMS device for imaging single cell response during quantitative force-displacement measurements. Biomedical Microdevices 10, 883-889.

Serrell, D.B., Oreskovic, T.L., Slifka, A.J., Mahajan, R.L., Finch, D.S., 2007. A uniaxial bioMEMS device for quantitative force-displacement measurements. Biomedical Microdevices 9, 267-275.

Shen, Z.L., Dodge, M.R., Kahn, H., Ballarini, R., Eppell, S.J., 2008. Stress-strain experiments on individual collagen fibrils. Biophysical Journal 95, 3956-3963.

Sim, W.Y., Park, S.W., Park, S.H., Min, B.H., Park, S.R., Yang, S.S., 2007. A pneumatic micro cell chip for the differentiation of human mesenchymal stem cells under mechanical stimulation. Lab Chip 7, 1775-1782.

Simson, D.A., Ziemann, F., Strigl, M., Merkel, R., 1998. Micropipet-based pico force transducer: in depth analysis and experimental verification. Biophysical Journal 74, 2080-2088.

Singer, W., Frick, M., Bernet, S., Ritsch-Marte, M., 2003. Self-organized array of regularly spaced microbeads in a fiber-optical trap. Journal of the Optical Society of America B 20, $1568-1574$.

Sleep, J., Wilson, D., Simmons, R., Gratzer, W., 1999. Elasticity of the red cell membrane and its relation to hemolytic disorders: an optical tweezers study. Biophysical Journal 77, 3085-3095.

Sniadecki, N.J., Anguelouch, A., Yang, M.T., Lamb, C.M., Liu, Z., Kirschner, S.B., Liu, Y., Reich, D.H., Chen, C.S., 2007. Magnetic microposts as an approach to apply forces to living 
cells. Proceedings of the National Academy of Sciences of the United States of America 104, 14553-14558.

Sniadecki, N.J., Lamb, C.M., Liu, Y., Chen, C.S., Reich, D.H., 2008. Magnetic microposts for mechanical stimulation of biological cells: Fabrication, characterization, and analysis. Review of Scientific Instruments 79, 1-8.

Song, J.W., Gu, W., Futai, N., Warner, K.A., Nor, J., Takayama, S., 2005. Computer-controlled microcirculatory support system for endothelial cell culture and shearing. Analytical Chemistry $77,3993-3999$.

Sotoudeh, M., Jalali, S., Usami, S., Shyy, J.Y.J., Chien, S., 1998. A strain device imposing dynamic and uniform equi-biaxial strain to cultured cells. Annals of Biomedical Engineering 26, 181-189.

Spero, R.C., Vicci, L., Cribb, J., Bober, D., Swaminathan, V., O’Brien, E.T., Rogers, S.L., Superfine, R., 2008. High throughput system for magnetic manipulation of cells, polymers, and biomaterials. Review of Scientific Instruments 79, 083707 (1-7).

Sukhorukov, V.L., Mussauer, H., Zimmermann, U., 1998. The effect of electrical deformation forces on the electropermeabilization of erythrocyte membranes in low-and high-conductivity media. Journal of Membrane Biology 163, 235-245.

Takahashi, K., Bulgan, E., Kanamori, Y., Hane, K., 2009. Submicrometer comb-drive actuators fabricated on thin single crystalline silicon layer. IEEE Transactions on Industrial Electronics 56, 991-995.

Tan, W., Scott, D., Belchenko, D., Qi, H.J., Xiao, L., 2008. Development and evaluation of microdevices for studying anisotropic biaxial cyclic stretch on cells. Biomedical Microdevices $10,869-882$.

Thoumine, O., Ott, A., Cardoso, O., Meister, J.J., 1999. Microplates: a new tool for manipulation and mechanical perturbation of individual cells. Journal of Biochemical and Biophysical Methods 39, 47-62.

Tkachenko, E., Gutierrez, E., Ginsberg, M.H., Groisman, A., 2009. An easy to assemble microfluidic perfusion device with a magnetic clamp. Lab Chip 9, 1085-1095.

Tsou, J.K., Gower, R.M., Ting, H.J., Schaff, U.Y., Insana, M.F., Passerini, A.G., Simon, S.I., 2008. Spatial regulation of inflammation by human aortic endothelial cells in a linear gradient of shear stress. Microcirculation 15, 311-323. 
Usami, S., Chen, H.H., Zhao, Y., Chien, S., Skalak, R., 1993. Design and construction of a linear shear stress flow chamber. Annals of Biomedical Engineering 21, 77-83.

Van Vliet, K.J., Bao, G., Suresh, S., 2003. The biomechanics toolbox: experimental approaches for living cells and biomolecules. Acta Materialia 51, 5881-5905.

Voldman, J., 2006. Electrical forces for microscale cell manipulation. Annual Review of Biomedical Engineering 8, 425-454.

de Vries, A.H.B., Kanger, J.S., Krenny, B.E., van Driel, R., 2004. Patterned electroplating of micrometer scale magnetic structures on glass substrates. Journal of Microelectromechanical Systems 13, 391-395.

de Vries, A.H.B., Krenny, B.E., van Driel, R., Kanger, J.S., 2005. Micro magnetic tweezers for nanomanipulation inside live cells. Biophysical Journal 88, 2137-2144.

Wang, J.H.C., Thampatty, B.P., 2006. An introductory review of cell mechanobiology. Biomechanics and Modeling in Mechanobiology 5, 1-16.

Wong, P.K., Tan, W., Ho, C.M., 2005. Cell relaxation after electrodeformation: effect of latrunculin a on cytoskeletal actin. Journal of biomechanics 38, 529-535.

Wu, V.C., Law, T., Hsu, C.M., Lin, G., Tang, W.C., Monuki, E.S., 2005. MEMS platform for studying neurogenesis under controlled mechanical tension, in: Proceedings of the 3rd Annual International IEEE EMBS Special Topic, pp. 408-411.

Yang, S., Saif, M.T.A., 2005. Reversible and repeatable linear local cell force response under large stretches. Experimental Cell Research 305, 42-50.

Yang, S., Saif, M.T.A., 2006. Force response and actin remodeling (agglomeration) in fibroblasts due to lateral indentation. Acta Biomaterialia 3, 77-87.

Yang, S., Saif, M.T.A., 2009. Microfabricated force sensors and their applications in the study of cell mechanical response. Experimental Mechanics 49, 135-151.

Yapici, M.K., Ozmetin, A.E., Zou, J., Naugle, D.G., 2008. Development and experimental characterization of micromachined electromagnetic probes for biological manipulation and stimulation applications. Sensors and Actuators A: Physical 144, 213 - 221.

Youn, S., Lee, D.W., Cho, Y.H., 2008. Cell-deformability-monitoring chips based on straindependent cell-lysis rates. Journal of Microelectromechanical Systems 17, 302-308.

Young, E.W.K., Wheeler, A.R., Simmons, C.A., 2007. Matrix dependent adhesion of vascular and valvular endothelial cells in microfluidic channels. Lab Chip 7, 1759-1766. 
Zhang, H., Liu, K.K., 2008. Optical tweezers for single cells. Journal of the Royal Society Interface 5, 671-690.

Zhang, W., Gnerlich, M., Paly, J.J., Sun, Y., Jing, G., Voloshin, A., Tatic-Lucic, S., 2008. A polymer V-shaped electrothermal actuator array for biological applications. Journal of Micromechanics and Microengineering 18, 075020 (8pp).

Zhu, Y., Corigliano, A., Espinosa, H.D., 2006. A thermal actuator for nanoscale in situ microscopy testing: design and characterization. Journal of Micromechanics and Microengineering 16, 242-253.

Zimmermann, U., Friedrich, U., Mussauer, H., Gessner, P., Hamel, K., Sukhorukov, V., 2000. Electromanipulation of mammalian cells: fundamentals and application. IEEE Transactions on Plasma Science 28, 72-82. 